\title{
3D study of morphology and dynamics of zeolite nucleation
}

Georgian Melinte, ${ }^{[\mathrm{a}]}$ Veselina Georgieva, ${ }^{[\mathrm{b}]}$ Marie-Anne Springuel-Huet, ${ }^{[\mathrm{c}]}$ Andreï Nossov, ${ }^{[\mathrm{c}]}$ Ovidiu Ersen, ${ }^{[\mathrm{a}]}$ Flavien Guenneau, ${ }^{[\mathrm{c}]}$ Antoine Gedeon, ${ }^{[\mathrm{c}]}$ Ana Palčić, ${ }^{[\mathrm{b}]}$ Krassimir N. Bozhilov, ${ }^{[\mathrm{d}]}$ Cuong Pham-Huu, ${ }^{[\mathrm{e}]}$ Shilun Qiu, ${ }^{[\mathrm{f}]}$ Svetlana Mintova ${ }^{[\mathrm{b}]}$ and Valentin Valtchev ${ }^{[\mathrm{b}]^{*}}$

${ }^{[a]}$ G. Melinte, Prof. O. Ersen IPCMS, Université de Strasbourg 23, rue du Loess BP 43, F-67034 Strasbourg, France

[b] V. Georgieva, Dr. A. Palčić, Dr. S. Mintova, Dr. V. Valtchev LCS, ENSICAEN - University of Caen - CNRS

6, Bd Maréchal Juin, 14000 Caen, France E-mail: valentin.valtchev@ensicaen.fr

${ }^{[c]}$ Dr. M.-A. Springuel-Huet, Dr. A. Nossov, Dr. F. Guenneau, Prof. A. Gedeon Laboratoire de Chimie de la Matière Condensée de Paris (LCMCP), Sorbonne Universités, UPMC Univ Paris 06, CNRS, Collège de France

11, place Marcelin Berthelot, 75005 Paris, France

${ }^{\text {[d] }}$ Dr. K. N. Bozhilov

Central Facility for Advanced Microscopy and Microanalysis, University of California, Riverside

900 University Avenue, Riverside, CA 92521, USA

${ }^{[\mathrm{e}]}$ Dr. C. Pham-Huu

ICPEES, ECPM, Université de Strasbourg

25, rue Becquerel, 67087 Strasbourg, France

[f] Prof. S. Qiu

State Key Laboratory of Inorganic Synthesis and Preparative Chemistry, Jilin University 2699 Qianjin Street, Changchun, Jilin 130012, China 


\begin{abstract}
The principle aspects and constrains of the dynamics and kinetics of zeolite nucleation in hydrogel systems are analyzed on the basis of a model Na-rich aluminosilicate system. A detailed time-series EMT-type zeolite crystallization study in the model hydrogel system is performed in order to elucidate the topological and temporal aspects of zeolite nucleation. A comprehensive set of analytical tools and methods is employed to analyze the gel evolution complementing the primary methods of transmission electron microscopy (TEM) and nuclear magnetic resonance (NMR) spectroscopy. TEM tomography reveals that the initial gel particles exhibit a core-shell structure. Zeolite nucleation is topologically limited to this shell structure and the kinetics of nucleation is controlled by the shell integrity. The induction period extends to the moment when the shell is consumed and the bulk solution can react with the core of the gel particles. These new findings, in particular the importance of gel particle shell in zeolite nucleation, can be used to control the growth process and properties of zeolites formed in hydrogels.
\end{abstract}

\title{
Introduction
}

Aluminosilicate zeolites are amongst the most widely used heterogeneous catalysts and molecular sieves in petroleum refining, petrochemistry, fine chemical production and pollutant abatement. ${ }^{[1,2]}$ Their application in large scale chemical processes and environmental protection is equally important. Hence, the engineering of zeolite materials remains a challenge that motivates academic and industrial researchers. This challenge is particularly important nowadays with the changes in quality and constitution of available fossil hydrocarbons that remain the most important energy sources, as well as the new implemented environment protection regulations. ${ }^{[3]}$ Often the zeolite crystals are subjected to post-synthesis modification in order to face the requirements of a particular chemical process. ${ }^{[4]}$ The successful use of post-synthesis methods, however, strongly depends on the intrinsic characteristics of zeolite crystals, that is, the way the crystals are synthesized. Thus, the fine control of zeolite formation is indispensable for the preparation of high quality materials and their further use.

The general model describing the zeolite formation mechanism was established long time ago. ${ }^{[5]}$ More detailed information on the mechanism of zeolite nucleation and schematic presentation of most important stages can be found in review articles. ${ }^{[6,7]}$ The classical theory used for describing the nucleation under hydrothermal conditions postulates that the system is expected to reach a certain level of supersaturation before the first nuclei are formed. ${ }^{[8]}$ Further, the viable nuclei grow at the expense of nutrient dissolved and transported via the supernatant to growing crystal. ${ }^{[9-11]}$ However, contemporary growth models agree that zeolite formation does not follow the classical model of crystallization in supersaturated systems. ${ }^{[12]}$ Something more, the reaction pathway depends on the initial composition and reactants used and may differ even for a particular zeolite. ${ }^{[13]}$ A zeolite framework type can be synthesized from different initial systems, ranging from optically clear water solutions through hydrogels to very thick gels. Although, structurally the products obtained from such systems are similar, their physical and chemical features usually are different. ${ }^{[14]}$ For instance, the particle size, morphology and the level of aggregation will be different for each of the above described initial systems. The zeolite nucleation is usually controlled by employing different initial systems ranging from very diluted solutions to extra dense gels. ${ }^{[15,16]}$ Microwave radiation or ultrasonic treatment are also used to 
promote a uniform nucleation in the system. Another commonly used approach is the introduction of zeolite seeds in the zeolite precursor system, thus controlling the issue of the synthesis kinetics of the process and the size of ultimate zeolite particles. ${ }^{[17,18]}$ Further, the chemical composition and the distribution of framework cations are controlled also by the employed initial systems. Therefore, the control of the nucleation process and the following crystallization steps is indispensable if the goal is the rational control of zeolite properties.

The understanding of zeolite growth mechanism has advanced substantially during the last decade. The use of very diluted systems containing well defined discrete particles allowed to shed more light in the formation of primary particles and their aggregation into larger units that exhibit long range order. ${ }^{[19-33]}$ Most of these studies were performed on transparent solutions obtained by mixing TPAOH - TEOS - $\mathrm{H}_{2} \mathrm{O}$ that yield silicalite-1 (MFI-type). Very recently, again such a solution was employed in an in situ AFM study with the goal to discriminate the species participating in the growth process. ${ }^{[34]}$ According to this study both silica molecules and preformed nanoparticles participate in the growth process showing again that the zeolite formation may include both classical and non-classical crystallization pathways.

Hydrogels containing alkali metal cations are used in the industrial mass production of zeolites. Such systems are not uniform; they exhibit distinct solid and liquid parts. Besides their physical appearance, the hydrogels are not uniform in chemical composition, which is due to uncontrolled polymerization of the silica/alumina species after mixing of the reactants. ${ }^{[35-40]}$ The so-called autocatalytic nucleation model was applied by Subotić and co-workers to explain crystal growth in such system. ${ }^{[41]}$ According to their model the nuclei are formed in the gel and liberated in the mother liquor before the growth ensues. Increase in the surface area of the growing nuclei accelerates the reaction rate. Thompson revised this model and postulated that the dormant nuclei are located near the surface of the gel particles. ${ }^{[42]}$ Our studies on very small initial gel particles showed that the nucleation and growth can take place via propagation of crystalline phase through the amorphous network. ${ }^{[43]}$ Nucleation and growth was observed in discrete gel particles that do not change substantially their size during the transformation of amorphous into crystalline material. The system used in the latter case was rich of organic structure directing agent and the crystallization was performed at room temperature. Lately, this crystallization mechanism was extended to organic template-free initial systems. ${ }^{[44,45]}$ The careful preparation of the initial systems allowed stabilization of the discrete gel particles, although the systems contained large amounts of sodium hydroxide. However, such conditions are difficult to be utilized on an industrial scale and the process of nucleation in mass production of zeolites is highly uncontrolled. Consequently, the crystalline products differ in size and level of aggregation. A better understanding of the mechanism of zeolite nucleation in conventional hydrogel system would allow better control of the growth process and consequently the properties of the final crystalline product.

Present study was performed on an EMT-type zeolite yielding system. EMT zeolite is the hexagonal counterpart of FAU-type material, the latter being the most important zeolite from industrial point of view. Similar to the FAU-type material, the EMT framework topology exhibits a three-dimensional large (12-membered ring) pore system. The major difference between two materials is that the cubic FAU polymorph features only one type of supercage (with a volume of $1.2 \mathrm{~nm}^{3}$ ), whereas the different stacking of faujasite sheets creates two cages in the EMT zeolite: a hypocage $\left(0.61 \mathrm{~nm}^{3}\right)$ and a hypercage $\left(1.24 \mathrm{~nm}^{3}\right){ }^{[46]}$ Thus the EMT material shows catalytic activity and selectivity different from FAU as a FCC catalyst. ${ }^{[47,48]}$ The objective of the present 
study is to explore the nucleation process in a conventional hydrogel system. More precisely, the goal is to determine the temporal and spatial aspects of the formation of the first nuclei by following the chemical and physical evolution of the solid phase. In order to reach this goal a system yielding a zeolite with great industrial potential was employed. The crystallization was performed at a temperature close to ambient conditions to slow down the crystal growth kinetics in order to distinguish between different crystallization steps The decrease of the crystallization temperature does not change the crystallization mechanism, but the kinetics of the reaction, as has been shown in previous studies performed with similar initial systems. ${ }^{[4,45,49]}$ Methods commonly used in the characterization of crystalline porous materials were employed. The study was primarily based on complementary TEM methods, as electron tomography (ET), high resolution TEM (HRTEM), and energy filtered TEM (EFTEM). TEM analyses were combined with hyper-polarized ${ }^{129} \mathrm{Xe}$ NMR, which was used to determine the first zeolite cages formed in the solid. Thus, a complete picture of physical and chemical changes in gel precursor was obtained.

\section{Results}

\section{General characterization}

The crystal growth kinetics was studied by XRD analysis. The obtained solids appeared amorphous up to $18 \mathrm{~h}$ of hydrothermal treatment (See Figure S1). Distinct diffraction peaks associated with EMT-type zeolite emerged after $24 \mathrm{~h}$ of hydrothermal treatment (Figure S1). The crystallinity increased gradually to $36 \mathrm{~h}$ of synthesis. Further extension of crystallization time did not result in a product with higher X-ray crystallinity. The XRD peaks were relatively large phenomenon, which was attributed to the small size of the crystalline domains. The $\mathrm{Si} / \mathrm{Al}$ ratio of the highly crystalline EMT-type zeolite obtained after $36 \mathrm{~h}$, determined by ICP analysis, was 1.2.

The SEM analysis of the samples confirmed that the gel and zeolite particles are very small and it was difficult to distinguish their detailed morphology. The zeolite crystals from longer run durations form complex aggregates with random shapes (Figure S2).

$\mathrm{N}_{2}$ sorption measurements corroborated the XRD data. The isotherms of the sample taken between 0 and $18 \mathrm{~h}$ are typical of non porous materials with negligible micropore volume. The specific surface area of these samples was also low. The initial gel exhibited a $S_{\text {BET }}$ of $12 \mathrm{~m}^{2} \mathrm{~g}^{-1}$ that corresponds to spherical particles with diameter of about $350 \mathrm{~nm}$. The specific surface area slowly increased during the induction period from 16 to $48 \mathrm{~cm}^{2} \mathrm{~g}^{-1}$ for the samples synthesized for 6 and $18 \mathrm{~h}$, respectively. Substantially different surface and porous characteristics could be observed after the formation of crystalline phase. The sample from run duration of $24 \mathrm{~h}$ exhibits type I isotherm (Figure S3). After rapid uptake at low relative pressure a slight inclination of the curve and a second uptake at high relative pressure could be observed. These particularities of the isotherm, which are not typical of crystalline microporous materials, revealed the presence of some mesopores. The samples synthesized for 30 and $36 \mathrm{~h}$ showed a slight increase of micropore volume, but the differences with the sample from the $24 \mathrm{~h}$ experiment were not significant. Therefore it could be concluded that the mass transformation from amorphous into crystalline EMT-type material took place between 18 and $24 \mathrm{~h}$ of treatment. The sample obtained after $24 \mathrm{~h}$ of hydrothermal treatment exhibits a $S_{\text {BET }}$ of $478 \mathrm{~cm}^{2} \mathrm{~g}^{-1}$ and micropore volume of $0.19 \mathrm{~cm}^{3} \mathrm{~g}^{-1}$.

TEM study 
The crystal growth kinetics of the system yielding EMT-type zeolite was followed by means of transmission electron microscopy. A collection of representative TEM images of amorphous precursors and crystalline product is shown in Figure 1.

Through conventional TEM imaging we were able to follow the morphological changes of the solid phase. The initial gel (Figure 1a) is built of oval gel particles creating more complex aggregates. The mesopores appear as "white spots" inside the gel network. ${ }^{[49]}$ These mesopores are filled with liquor from the mother solution as shown in the Movie 1 (Supplementary information). To verify this interpretation the high energy electron beam was focused in a probe with small diameter and high beam current on a nanometric gel particle causing rapid increase in the temperature of the irradiated zone. This led to disappearance of most of the mesopores by forcing the liquid outside the pores and inducing secondary phase growth (see Movie 1, Supplementary information).

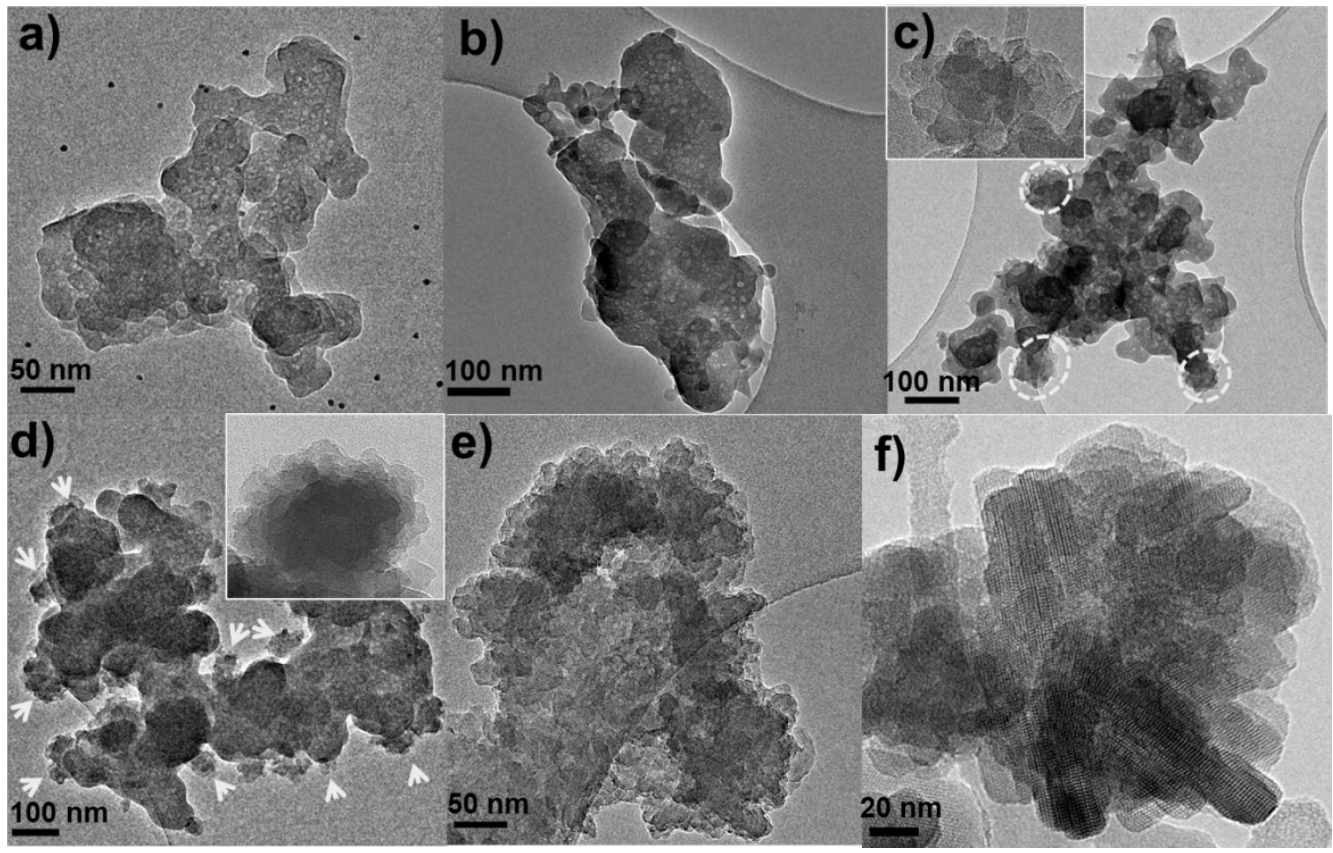

Figure 1. TEM images of the solid phase obtained in the system yielding EMT-type zeolite at 313 $\mathrm{K}$ : a) initial gel $(0 \mathrm{~h})$, b) $6 \mathrm{~h}, \mathrm{c}) 12 \mathrm{~h}$, d) $18 \mathrm{~h}$, e) $24 \mathrm{~h}, \mathrm{f}) 36 \mathrm{~h}$. The white ellipsoids (c) and arrows (d) highlight the presence of crystalline non-porous areas (see the insets).

The morphology of the gel changed after $6 \mathrm{~h}$ of hydrothermal treatment (Figure 1b). The individual gel particles could be distinguished more easily and the presence of straight edges points towards development of certain order within the solid. The "white spots" attributed to mesopores were observed as well. Crystalline particles aggregates with size of about $50 \mathrm{~nm}$ built up by very small crystallites were clearly identified after $12 \mathrm{~h}$ of crystallization (Figure 1c-white ellipsoids). Very few crystalline particles could be identified in the solid, while the amorphous particles did not change substantially their physical appearance in respect to the $6 \mathrm{~h}$ sample. The area occupied by the crystalline regions and their abundance continued to increase for the $18 \mathrm{~h}$ sample (Figure 1d-white arrows). It is worth recalling that the XRD pattern of the sample did not 
reveal presence of crystalline phase at this stage (Figure S1). The mass of crystalline phase and the size of the crystallized domains are obviously below the detection limit of XRD technique, which is between 3 and $5 \mathrm{wt}$. \%. The product obtained after $24 \mathrm{~h}$ consisted mostly of crystalline zeolite (Figure 1e). Porous amorphous particles were replaced completely by apparently nonporous crystalline aggregates. An image of the completely crystallized zeolite obtained after $36 \mathrm{~h}$ of treatment is presented in Figure 1f.

The data above provides only a macro-morphological description of the solid phase without offering an insight into the nanoscale features (molecular level). Since conventional TEM imaging provides essentially a $2 \mathrm{D}$ projection of $3 \mathrm{D}$ objects and features, it offers limited information about the topology, size distribution, and spatial connectivity in the case of a complex porous network inside aggregates such as we have in the studied samples. We have attempted to resolve this limitation by utilizing the capabilities of electron tomography (ET). Further to ensure that the porous structure is preserved intact and not modified by electron beam interaction, cryo-TEM at $203 \mathrm{~K}$ was utilized to collect TEM images for tomography reconstruction.
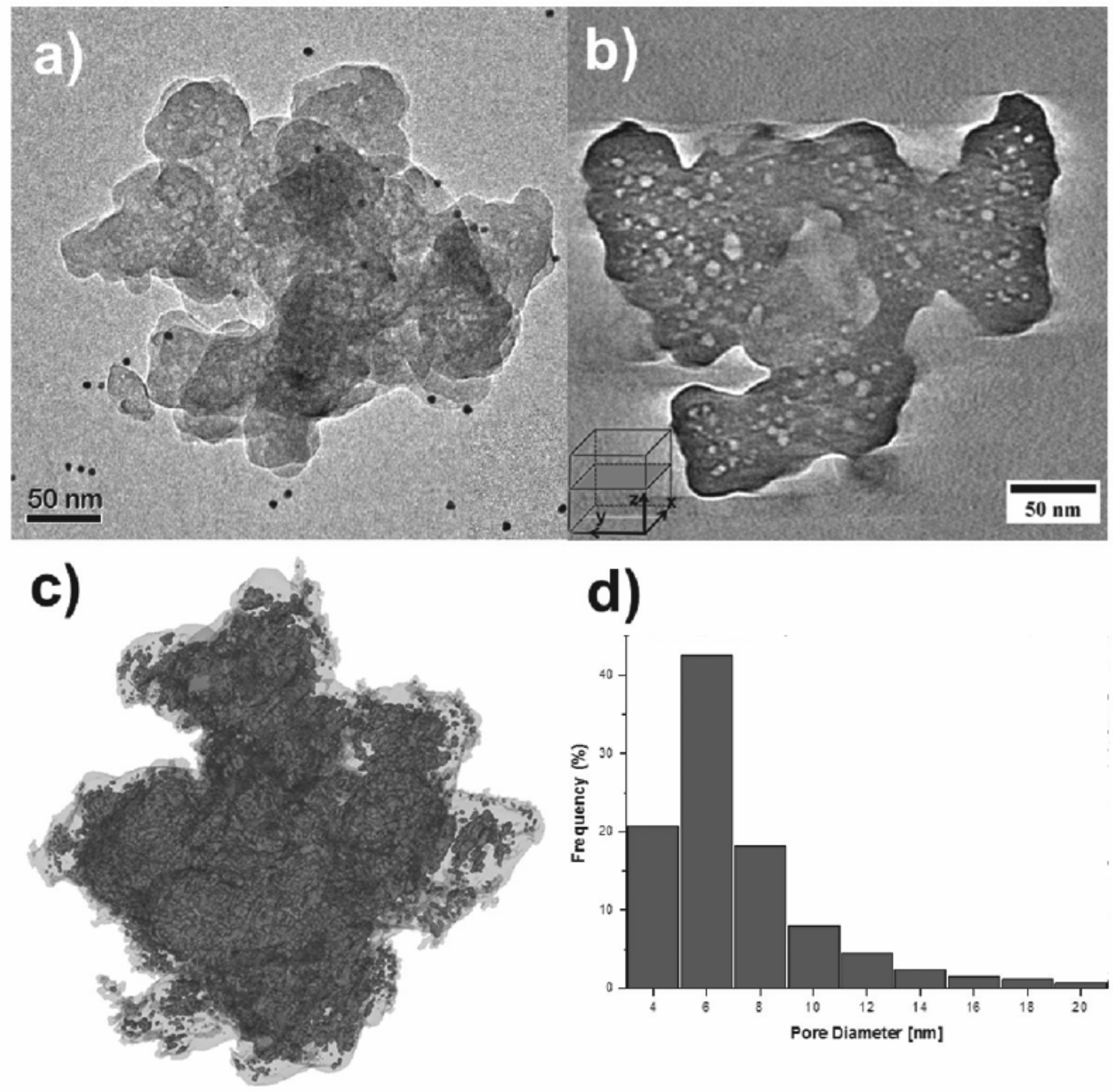
Figure 2. a) Conventional TEM image of a gel particle form the initial run ( $0 \mathrm{~h})$ used for cryo-ET; b) XY slice through the reconstructed volume of the gel particle; c) general view after segmentation of the gel particle (pores are represented in dark grey and the gel body in semitransparent grey); d) pore size distribution in the gel particle extracted from the cryo-ET segmented data.

A conventional TEM image at $0^{\circ}$ tilt of the specimen from the initial run $(0 \mathrm{~h})$ is shown in Figure 2a. The existence of the porous structure can be observed clearly. However, useful information is difficult to extract due to the 2D nature of the TEM images and the overlap of features positioned at different depth along the electron beam direction. Figure $2 \mathrm{~b}$ shows a XY slice (thickness of $0.25 \mathrm{~nm}$ normal to the plane of view) extracted digitally from a cryo-tomogram created by acquiring tilt-series of images from the gel particle shown in Figure 2a. It can be observed easily that the pores, between 3 and $20 \mathrm{~nm}$ in diameter are uniformly distributed throughout the gel particle volume. It is important to note, that the pores do not communicate directly with the external surface of the gel particle. A non-porous zone with a thickness of about 7 to $15 \mathrm{~nm}$ covers the entire gel particle and seals the pores inside. To assess the detailed 3D topology of the pore structure the gel particle volume was reconstructed from the tilt-series images. Figure 2c represents an image of the reconstructed gel particle, obtained after segmentation, where the pores are represented in dark grey and non-porous part in semi-transparent grey. The generated model (see Movie 2, Supplementary information) shows clearly that the surface of the gel particle is depleted of pores, which tend to be concentrated in the particle center. A quantitative porosity analysis (see Materials and Methods) reveals an overall porosity of about $22 \%$. The pore size distribution (represented as a function of the frequency of abundance) extracted from the reconstructed volume is centered on $\sim 6 \mathrm{~nm}$ with more than $40 \%$ of the pores having a diameter between 5 and $7 \mathrm{~nm}$.

The gel treated hydrothermally for $6 \mathrm{~h}$ showed the same porous features as the initial gel obtained at room temperature (Figure 3a). However, the appearance of small faceted non-porous regions (dashed rectangles) with straight edges reveals that the crystallization process had already started. The extreme instability of these crystalline-appearing features under the electron beam even under cryo-TEM conditions precluded direct confirmation by electron diffraction or lattice imaging of a long-range order for the sample treated for $6 \mathrm{~h}$. However, analysis of the subsequent evolution stages of the crystallization process showed clearly that the zeolite's crystallization starts within these faceted regions. The regions with faceted morphology did not contain any pores (Figure 3a). At the $6 \mathrm{~h}$ stage a few of these crystalline particles were observed. They form $10-20 \mathrm{~nm}$ aggregates situated in the peripheral part of much larger amorphous aggregates. It is difficult to determine whether the crystalline particles are isolated or a continuous part of the amorphous aggregate they are attached to. Most of them are isometric suggesting that crystallization most probably took part around a single crystallization center. The size and abundance of these faceted non-porous regions increased for the sample treated for $12 \mathrm{~h}$ suggesting a more extensive process of reorganization and condensation of the aluminosilicate species. Figure $3 \mathrm{~b}$ presents a particle from the $12 \mathrm{~h}$ experiment with such a dual morphology. A HR-TEM confirmed unambiguously the crystalline order and the presence of zeolite micropores (Figure 3c inset). The regions comprising these primary zeolite crystals are localized exclusively in areas free of pores and in the shell of the original gel particles (Figure 2c). 
The XY slices (Figure 3c and d) through the reconstructed volume of a particle clearly show the difference in morphology between porous and non-porous regions in the sample treated for $12 \mathrm{~h}$. Furthermore, the morphology of the non-porous regions had changed by developing rough faceted exterior surfaces with an acicular aspect and the abundance and relative volume of these regions had increased compared with the $6 \mathrm{~h}$ sample. Interestingly, a small fleck is situated inside each mesopore (from the amorphous area) close to its center. The presence of small flecks in the mesopores was observed in each of five gel particles subjected to analysis. Evidently these flecks were formed in the process of gel evolution in the time interval between 6 and $12 \mathrm{~h}$. It can be inferred that the mother liquor imprisoned during the initial gel formation has reacted with the aluminosilicate network and has yielded these solid particles. The attempts to obtain high resolution images or selected area electron diffraction (SAED) of such particles were not successful due to their instability under the electron beam. It was not possible to determine their chemical composition either. The solid particles observed inside the mesopore space could be a metastable phase that disappears in the process of zeolite formation.

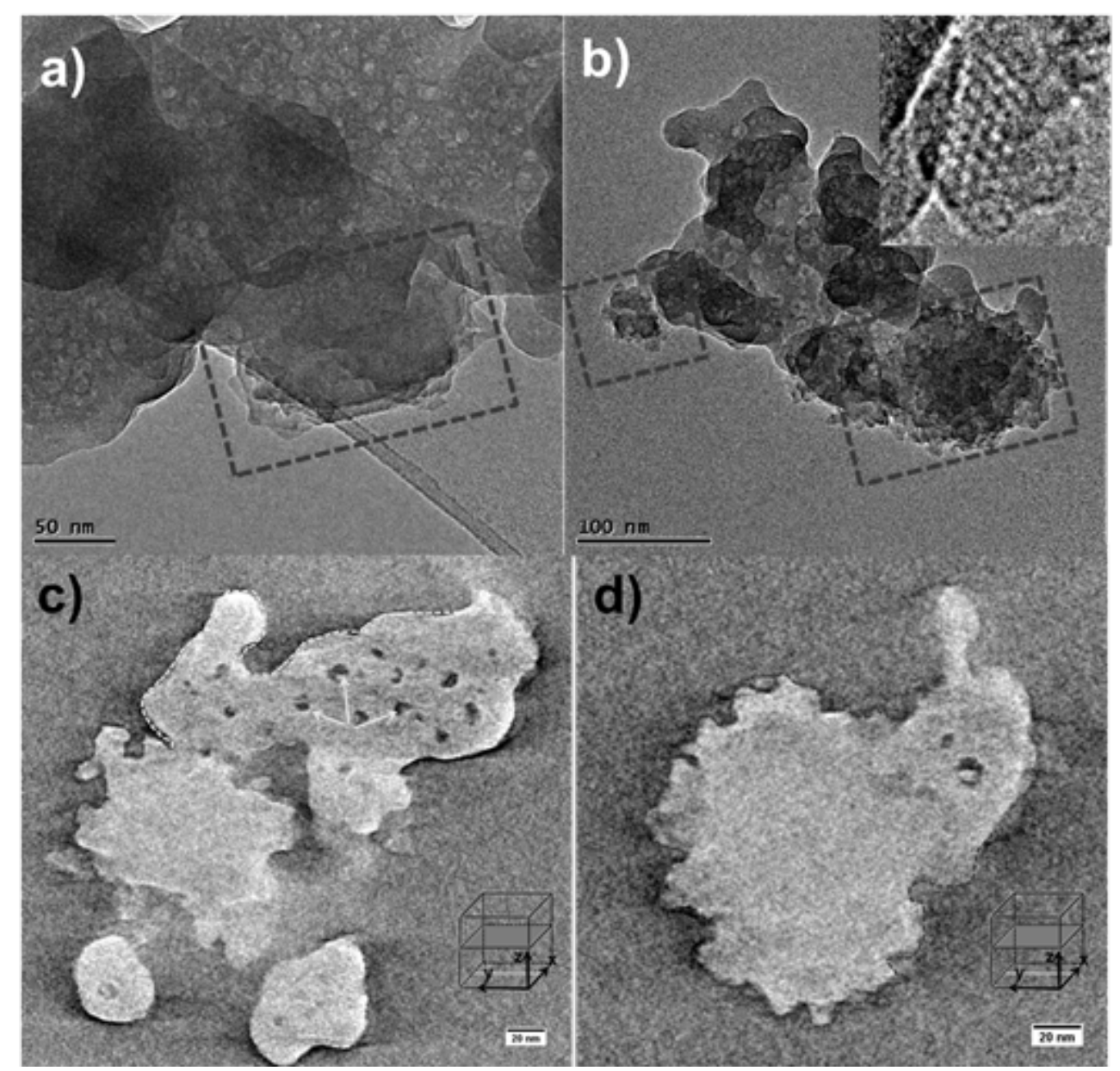

Figure 3. a) TEM image of a $6 \mathrm{~h}$ zeolite particles with a dual morphology: porous and non-porous (dashed rectangles); b) $12 \mathrm{~h}$ zeolite sample with a dual morphology (the inset is a HRTEM image of the microporous cages formed in the non-porous regions (dashed rectangle); c) and d) XY slices through the reconstructed volume of a $12 \mathrm{~h}$ zeolite sample. 
Cryo-electron tomography (cryo-ET) was performed on the $12 \mathrm{~h}$ sample in order to obtain quantitative information about the morphology, topology, distribution, and size of the mesopores. Figure $4 \mathrm{a}$ shows a conventional TEM image of a gel particle at $0^{\circ}$ tilt, while Figure $4 \mathrm{~b}$ shows a $\mathrm{XY}$ slice through its reconstructed volume. The pore distribution inside the $12 \mathrm{~h}$ hydrothermally treated particle is similar to the initial gel particle $(0 \mathrm{~h})$. The cavities are isolated and do not communicate with the external surface of the gel particle (see Figure 4c and Movie 3, Supplementary information). Moreover, the pore size distribution is also centered around $6 \mathrm{~nm}$ but with a small $(5 \%)$ decrease in number for the $5-7 \mathrm{~nm}$ region and a $10 \%$ increase for the $3-5$ $\mathrm{nm}$ region. The porosity of the core part for the $12 \mathrm{~h}$ sample is lower $(\sim 17 \%)$ than the initial gel porosity $(\sim 22 \%)$. The overall porosity, including the non-porous crystalline regions, is about $14 \%$. The pore size distribution is centered around $5 \mathrm{~nm}$.
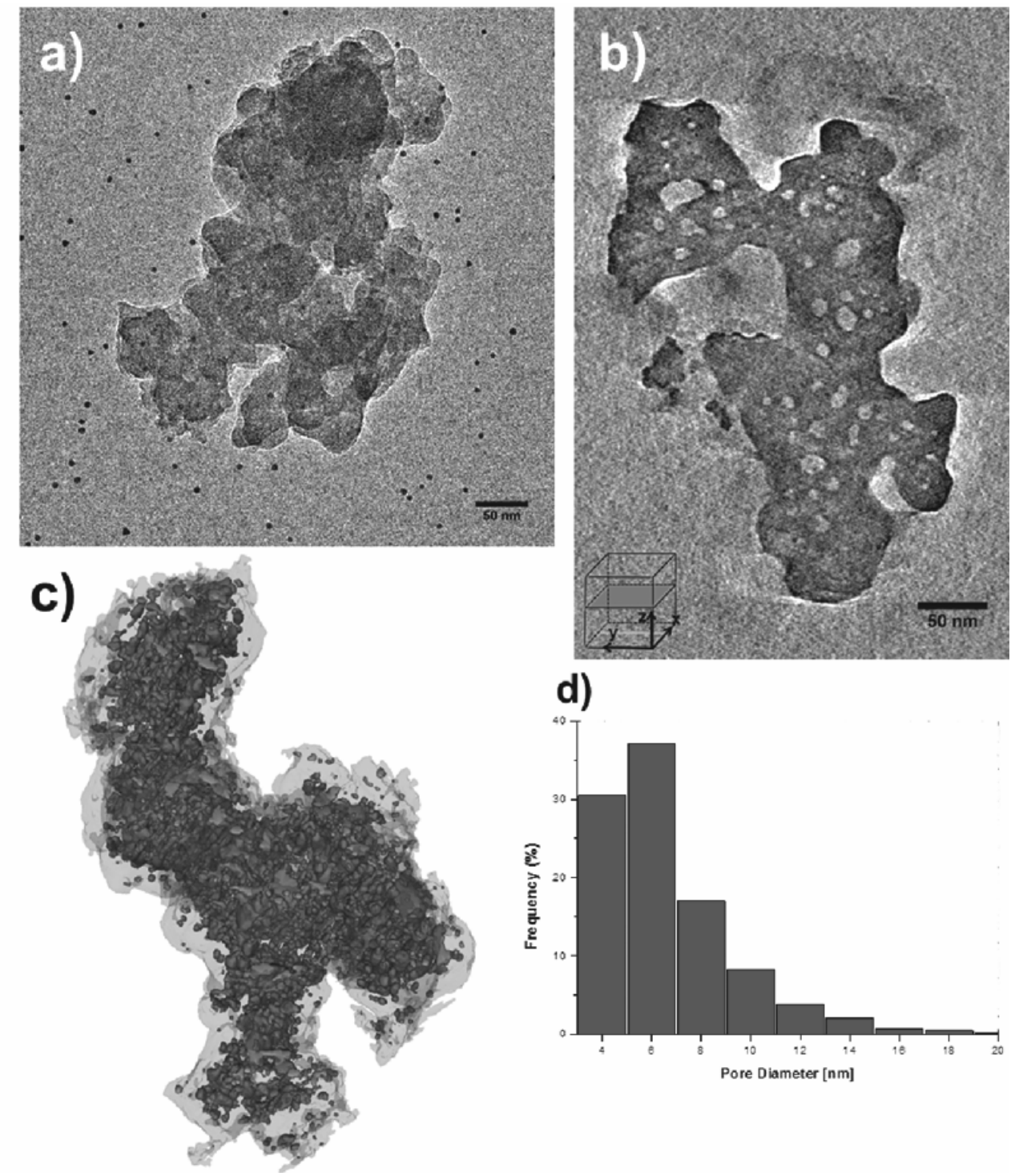

Figure 4. a) Conventional TEM image at $0^{\circ}$ tilt of a gel particle from the sample treated hydrothermally for $12 \mathrm{~h}$; b) XY slice through the reconstructed volume of the particle in Figure 4a obtained by cryo-ET; c) digitally reconstructed gel particle after segmentation: pores are 
represented in dark grey and the gel body in semi-transparent grey; d) pore size distribution of the $12 \mathrm{~h}$ sample extracted from the cryo-ET data.

The solid particles exhibit the same dual morphology after $18 \mathrm{~h}$ of hydrothermal treatment (Figure 1d). However, the volume fraction of the non-porous regions has increased at the expense of porous ones. The mass transformation of amorphous into crystalline type material took place between 18 and $24 \mathrm{~h}$. As can be seen in Figure 5a, the solid particles of the $24 \mathrm{~h}$ sample are aggregates of nanosized crystallites. In the core of aggregates the crystals are smaller $(10-20$ $\mathrm{nm}$ ) and do not exhibit a defined morphology, while at the periphery the typical for EMT-type zeolite hexagons with platy morphology can be seen. The surface of aggregates has jagged outlines due to the well developed faces of individual crystals. Figure $5 \mathrm{~b}$ shows a XY slice through a zeolite aggregate particle from the $24 \mathrm{~h}$ sample reconstructed digitally from cryo-ET data. It highlights the exterior surface roughness and the complete disappearance of mesopores abundant in the amorphous precursor. The morphology of the zeolite aggregates obtained after 30 $\mathrm{h}$ of treatment resembles those from the $24 \mathrm{~h}$ sample. However, the formation of prismatic elongated nanostructure (highlighted by white dotted lines) on their surface can be observed easily (Figure 5c). As the HR-TEM images in Figure 5d shows, the zeolite crystallization seems to have been completed after $30 \mathrm{~h}$.

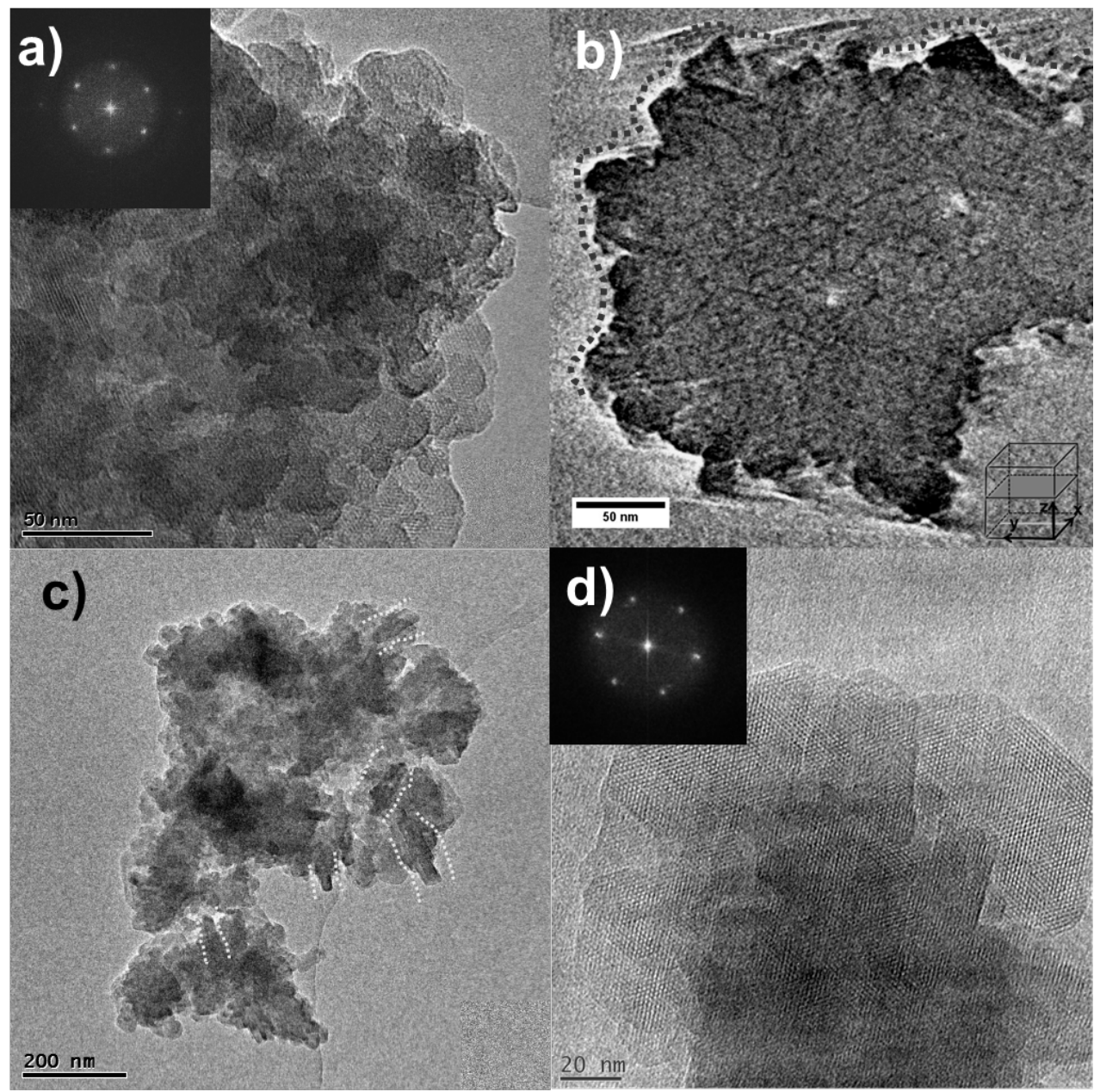


Figure 5. a) TEM image of a $24 \mathrm{~h}$ zeolite sample with its FFT inset; b) XY slice through the reconstructed volume of a $24 \mathrm{~h}$ zeolite sample, grey dotted line outlines the jagged outer edges of the aggregate particle; c) conventional TEM image of a $30 \mathrm{~h}$ zeolite sample with the prismatic structure highlighted with white dotted lines; d) ABSF filtered HRTEM image of a $30 \mathrm{~h}$ sample with its FFT inset.

\section{Analytical TEM investigations}

The spatial distribution of the Si and Al was investigated using energy filtered TEM (EFTEM). The instability of the specimens under the high energy electron beam, especially for the amorphous particles, limited the analysis to $\mathrm{Si}$ and $\mathrm{Al}$. Oxygen and sodium maps were not acquired. The statistical analysis of the Si and Al distributions (between 5 and 10 grains selected for each sample) showed that both elements are homogeneously distributed in the individual gel particles and crystalline aggregates throughout the entire hydrothermal treatment. Supplementary Figure S4a shows elemental maps of a gel particle while in Figure S4b the maps of a $12 \mathrm{~h}$ sample with a dual porous and non-porous morphology is presented. As can be observed there is no difference in the elemental distribution between the porous region (amorphous) and the nonporous one (crystalline). The almost fully crystalline $24 \mathrm{~h}$ zeolite grain (Figure S4c) shows the same homogeneity. Nevertheless, a small increasing in the Al concentration on the grains edges is occasionally observed. The energy dispersive X-ray spectroscopy (EDS) showed a small change in the concentration of the alumina and silica species between the initial gel and the final zeolite sample. The average anhydrous composition normalized to $100 \%$ and excluding $\mathrm{Na}_{2} \mathrm{O}$ is $\mathrm{Al}_{2} \mathrm{O}_{3} 43.6$ wt. \% and $\mathrm{SiO}_{2} 56.4 \mathrm{wt} \%$ for the particles in the initial gel, while after $30 \mathrm{~h}$ of treatment the composition is $45.7 \% \mathrm{Al}_{2} \mathrm{O}_{3}$ and $54.3 \% \mathrm{SiO}_{2}$

\section{Raman study}

Raman spectroscopy is used often to study the extent of polymerization of the $\mathrm{SiO}_{4}$ tetrahedra, their connectivity and the formation of different ring structures in zeolite materials. We have employed Raman analysis to examine the changes in the solid during the induction period (from 0 to $24 \mathrm{~h}$ treatment). During the first $12 \mathrm{~h}$ no substantial changes in the gel structures were detected (Figure S5). Only a broad peak at about $500 \mathrm{~cm}^{-1}$ was observed which is characteristic for four member rings (4MRs) in tectosilicate structures formed by four $\mathrm{Si}(\mathrm{Al}) \mathrm{O}_{4}$ tetrahedral sharing two common oxygen atom. ${ }^{[50]}$ Obviously these are the units that dominate the amorphous material. The intensity of the peak at $500 \mathrm{~cm}^{-1}$ is increased significantly for the $18 \mathrm{~h}$ sample suggesting that the $4 \mathrm{MRs}$ have become more rigid, statistically more prominently present and they are most probably integrated in larger structures. The broad character of the peak is preserved confirming that there is still significant degree of disorder and randomness in the polymerization among the aluminosilicate tetrahedra. Two additional new weak peaks can be distinguished in the spectrum of this sample. The one at $380 \mathrm{~cm}^{-1}$ could be attributed to 6member rings typically present in sodalite cages. ${ }^{[51]}$ The second peak, at $290 \mathrm{~cm}^{-1}$, is characteristic for rings formed by more than 6 tetrahedra. In the present case this peak could be attributed to 12-member ring pore opening typical for the EMT-type structure. ${ }^{[51]}$ The appearance of these two peaks suggests that a certain number of EMT-cages have been formed in the solid after $18 \mathrm{~h}$ of treatment. The XRD pattern of this material (Figure S1) lacks any peaks indicating that the polymerization of the aluminosilicate tetrahedra has mostly short range extent and it lacks the extended long range periodicity typical for crystalline matter. Based on these results, 
one can conclude that, the starting gel has undergone significant reorganization after $18 \mathrm{~h}$ of treatment and EMT-type units are formed and stably present in the amorphous gel particles but the connectivity between the individual units is limited and no long-range order exists. The fast crystalline growth between 18 and $24 \mathrm{~h}$ of hydrothermal treatment supports this interpretation.

The characterization of the synthesis run products in this study by XRD and TEM showed that after $24 \mathrm{~h}$ of hydrothermal treatment the samples are crystalline. Although the $30 \mathrm{~h}$ sample is highly crystalline we have used the $36 \mathrm{~h}$ synthesized sample for ${ }^{129} \mathrm{Xe}$ NMR study in order to further minimize any possible interference by amorphous material. Variable-temperature (between 296 and $128 \mathrm{~K}$ ) spectra of the sample measured with hyperpolarized xenon are presented in Figure 6. At $296 \mathrm{~K}$, in addition to the gas phase line at $0 \mathrm{ppm}$, the spectrum exhibits a single line, at $85 \mathrm{ppm}$, corresponding to adsorbed xenon. This shift is completely consistent with the ${ }^{129}$ Xe NMR spectrum that we recorded with a reference EMT-type sample synthesized with 18-crown-6 ether as templating agent. ${ }^{[52]}$ As temperature decreases, its chemical shift increases and the signal splits into two components which become broader. Spectra were also recorded with the lasers off at temperatures below $213 \mathrm{~K}$. Under such conditions one peak is present corresponding to the high chemical shift line of the HP spectra. This peak is due to purely thermally-polarized Xe below $193 \mathrm{~K}$ proving that the HP Xe nuclei lose their polarization rapidly in the zeolite pores and are not exchanged by HP Xe during the time delay between two subsequent radiofrequency pulses. The low-chemical-shift peak, appearing when temperature is decreased, can be attributed to the fraction of Xe atoms exchanging between the gas phase and adsorbed phase. This line is characteristic for HP Xe, since it disappears when the laser is switched off. The presence of such an exchange is not surprising since the crystals have nanometric size and the Xe atoms may diffuse in and out of the crystallites during the NMR measurement timescale. If the pore space or gaps between the crystalline particles are reduced, for example when the powder sample is compressed, then the intensity of this peak decreases and ultimately disappears at $T<173 \mathrm{~K}$ (Figure S6).

At room temperature, the two peaks cannot be distinguished because all the adsorbed Xe atoms are in exchange with the gas phase. As the temperature decreases, the mobility of Xe atoms decreases and one can consider two parts in zeolite crystals: an inner part where the Xe atoms cannot exchange with the outer gas phase and a peripheral one where the Xe atoms can exchange. ${ }^{[53]}$

The EMT zeolite structure presents large pores. Therefore, a rapid diffusion of adsorbed Xe atoms is expected. As a result, an exchange with the gas phase within the acquisition time (few $\mathrm{ms}$ ) would not be surprising especially when crystals are small, even at low temperature. The presence of two lines at $\mathrm{T} \leq 213 \mathrm{~K}$ shows that it is not the case. This observation could be explained by the high $\mathrm{Na}^{+}$content in the synthesized low silica EMT zeolite. Most probably the $\mathrm{Na}$ cations hinder the movement of Xe inside the crystals. 

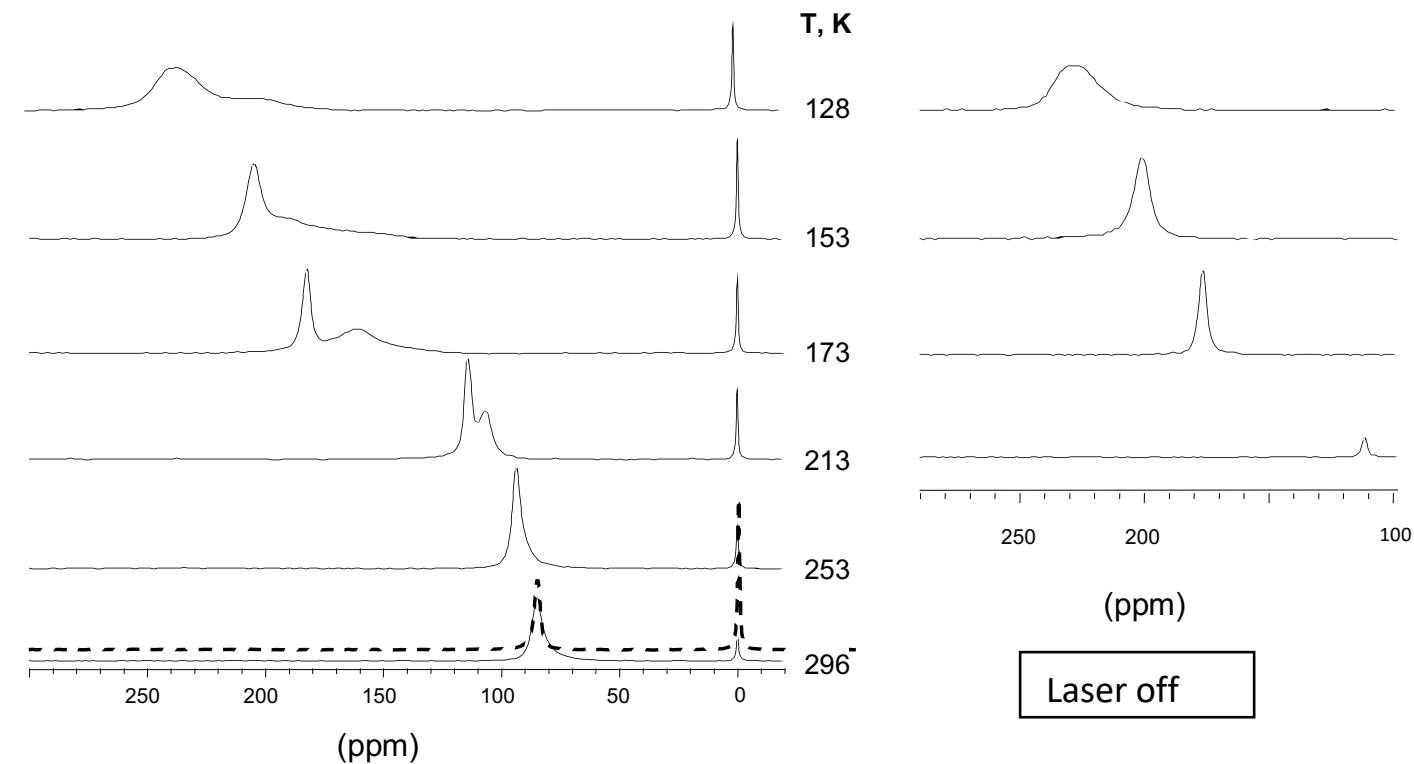

Figure $6 .{ }^{129} \mathrm{Xe}$ NMR spectra versus temperature of xenon adsorbed in the sample from the $36 \mathrm{~h}$ run duration. On the right hand side, spectra recorded with the lasers off (for $T \leq 213 \mathrm{~K}$ ). A spectrum of EMT sample synthesized with 18-crown-6 ether is shown by a dashed line. The intensity of the spectra is arbitrary.

The chemical shift variation of the characteristic NMR peaks of EMT is plotted versus temperature for the series of samples prepared for different synthesis time and the reference sample synthesized with 18-crown-6 ether (Figure 7). The shape of the curves is generally normal and within the expected behavior and the low-field signal can be attributed to the EMT structure. The increase in chemical shift with decreasing temperature, occurring essentially at temperatures below $220 \mathrm{~K}$, is due to the increase in the residence time of the Xe atoms on the surface and the increase in the Xe-Xe interactions on the surface as well. The variable-temperature experiments are performed with $\mathrm{HP}{ }^{129} \mathrm{Xe}$ under continuous flow, thus the sample remains at adsorption equilibrium at any temperature and the amount of adsorbed Xe becomes rather large when the temperature approaches the temperature of phase transformation of the bulk phase (about $115 \mathrm{~K}$ at 8 Torr Xe pressure).

There are some small deviations from the expected behavior in the high-temperature region, for instance the curves for all samples are at higher ppm values than the reference EMT sample. The differences could be attributed to reduction in the average size of the channels possibly due to structural distortions or/and to difference in the accessibility of the cages due to the interference of the increased $\mathrm{Na}^{+}$content. In the low-temperature region, the chemical shifts of the run products are smaller than that of the reference. This might be a consequence of slightly reduced volume of the EMT cages caused by distortions or specific position of $\mathrm{Na}^{+}$cations. 


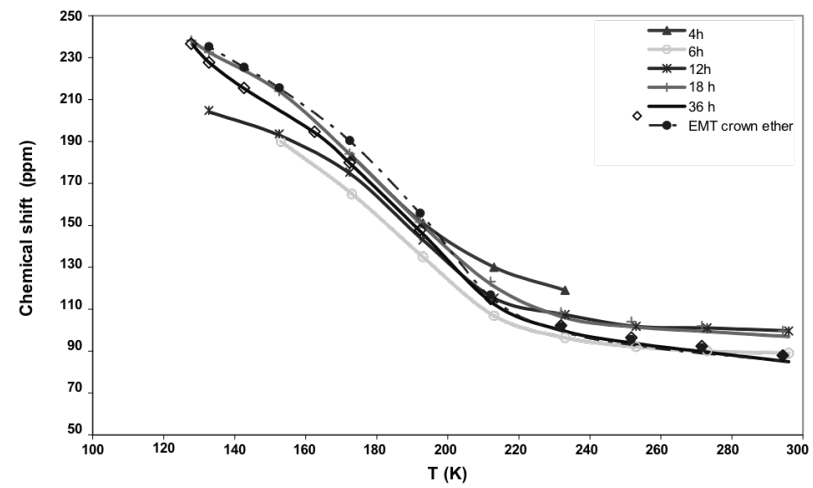

Figure 7. Chemical shift variation of the NMR peaks versus temperature for the experimental samples obtained in different synthesis run duration $(\mathrm{h})$ compared to the reference EMT sample synthesized with 18-crown-6 ether.

The intensity of the NMR peaks from the EMT structure was fairly intense after $6 \mathrm{~h}$ of hydrothermal treatment. In order to determine when the first EMT cages appear in the solid phase we have studied the samples subjected to 2 and $4 \mathrm{~h}$ hydrothermal treatment. First traces of EMTlike cages were detected for the $4 \mathrm{~h}$ sample at $T \leq 233 \mathrm{~K}$. At higher temperature, the amount of Xe adsorbed in the EMT phase is smaller and the signal is too weak to be observed.

Figure 8 shows the spectra recorded at $193 \mathrm{~K}$ of samples synthesized at different synthesis times. The signal characteristic of EMT-type material, around $145 \mathrm{ppm}$, is highlighted by a square on each spectrum. For the samples synthesized between 4 and $18 \mathrm{~h}$ the signal is broad, possibly due to the exchange of Xe between the EMT cages and larger cavities, the latter could be the intrinsic gel mesopores or the textural mesopores between the gel particles.

The other signals, at lower chemical shifts, differ drastically from one sample to another. They are due to $\mathrm{Xe}$ atoms interacting with an amorphous phase having a more or less structured mesoporosity and exchanging between various environments and the gas phase. One cannot derive precise information from this part of the spectra because it depends on many parameters including the morphology of the voids, their relative amount, their connectivity and the degree of polarization of the Xe nuclei. The presence of a narrow and intense signal observed in the fully amorphous sample reveals the existence of well-defined meso-voids in the initial gel. The average size of these voids can be estimated from the chemical shift of the signal measured at 296 $\mathrm{K}(22 \mathrm{ppm})$ and using the relationship between the chemical shift, $\delta$, and the mean pore size, $D$, established by Terskikh et al. ${ }^{[54]}$ for silica gels: $\delta=118 /(1+D / 122)$. A value of $5.3 \mathrm{~nm}$ is obtained. We attribute this signal to the mesocavities in the rim of gel particles. This suggestion is 


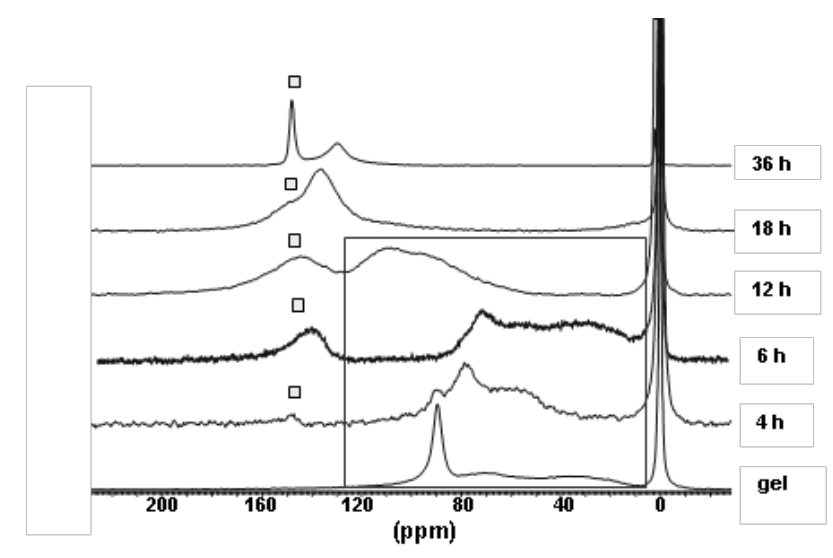

Figure $8 .{ }^{129} \mathrm{Xe}$ NMR spectra recorded at $193 \mathrm{~K}$ of xenon adsorbed in the initial gel and samples obtained after various synthesis times. The signal characteristic of the EMT structure is highlighted with squares and the lines corresponding to amorphous phase not well structurally organized are surrounded by a rectangle. The intensity of the spectra is arbitrary.

supported by the fact that this signal decreases for the $4 \mathrm{~h}$ sample, when first zeolite cages are detected. Hence, one may speculate that the mesopore cages close to the surface might be a preferential place for the zeolite nucleation. In any case, the process of reorganization is limited to the shell of gel particles and includes negligible part of the mass of the solid because the other methods employed, that is, XRD for long range order and Raman spectroscopy for short range order, did not detect any changes in this stage of gel evolution.

After $4 \mathrm{~h}$ of hydrothermal treatment a low-field shift and broadening of the mesopore peak is observed (Figure 8). This trend is much pronounced in the $6 \mathrm{~h} \mathrm{sample.} \mathrm{These} \mathrm{are} \mathrm{clearly}$ indications that some changes in the solid phase take place that change the structure of mesoporous voids and their accessibility by gas phase Xe. After $18 \mathrm{~h}$ of hydrothermal treatment the peaks corresponding to Xe exchange with mesopores are not observed in the spectra, although still amorphous phase containing mesopores is present as shown by TEM tomography analysis. This fact is due to increased mass of microporous phase (EMT), where the Xe atoms are preferentially adsorbed.

\section{Discussion}

It is common knowledge at present that zeolite nucleation is a heterogeneous reaction, which is supported by both theoretical ${ }^{[55,56]}$ and experimental ${ }^{[43,57]}$ studies. All zeolite yielding systems are heterogeneous in nature, comprising a solid and liquid phase. The nucleation process is a consequence of the reactions between these parts of the system. Chemical concentration and potential gradients between solid and liquid phase are the driving force for the exchange of species that leads to certain degree of homogenization of the system. Ultimately the dissolution, transport and precipitation of the reactive species produce supersaturation that induces nucleation. Such intense exchange between the solid and liquid parts of one hydrogel continues during the crystal growth process until complete exhaustion of nutrients in the system. Thus, the solid and liquid parts in a zeolite yielding system are equally important, as each part has a specific function. Investigating the reactions in the liquid part is difficult, even by in-situ 
methods, because of the heterogeneity of the zeolite precursors and the numerous metastable equilibrium steps that a system passes through. The evolution of the gel leading to crystalline final products can be tracked more easily by studying the solid part of the gel. Furthermore, up till now direct observation of the process of birth of the first zeolite cages has been observed only in a solid phase, although in a very particular zeolite yielding system. ${ }^{[43]}$ The main objective of the present study as motivated by the preceding considerations was to study in depth the changes in the solid phase pertinent to zeolite nucleation. The polymerization reaction between the two initial solutions was designed as a way to form aggregated zeolite particles, which are easy to separate from the mother liquor. Certainly sub-colloidal particles remained in the liquid phase, but their impact on the overall process of zeolite formation is considered negligible.

The TEM investigation revealed that the initial mixing of the two starting solutions produced relatively large gel aggregates although the mixing was performed under vigorous stirring. The internal part of the gel aggregates comprised abundant mesopores and mesocavities. Mother liquor was imprisoned in these meso-voids. Considering the initial gel composition and the fact that most of the aluminosilicate precursors polymerize almost instantly, the liquid in voids must be rich in $\mathrm{Na}^{+}$and $\mathrm{OH}^{-}$and low-weight silica/alumina species. Each particle has a shell, which contains only a few mesocavities. This shell built of densely polymerized aluminosilicates is not permeable to fluids. The high stability of the shell structure is proven by the fact that it survives the purification procedure, the drying, and even the $\mathrm{N}_{2}$ adsorption experiments. The low specific surface area of the initial gel supports further the latter statement. Only under focused high energy electron beam the shell was destroyed liberating the imprisoned fluid as can be seen in Movie 1 (Supplementary information). This new finding reveals that in the beginning of the nucleation process only the external surface of the gel particles is accessible for the bulk liquid. Therefore, the relative fraction of solid surface reacting with the mother liquor is limited considerably in the beginning of the process. This is the most probable reason for the long induction period and limited crystallization during the first $18 \mathrm{~h}$ of hydrothermal treatment. Progressively, the non-porous domains of the gel were converted in zeolite type crystals, decreasing the thickness of the impermeable gel shell. After $18 \mathrm{~h}$ of hydrothermal treatment most of the particles shell is dissolved and the access to the core rich in mesocavities is opened. This is the exact temporal location in the sequence of reaction events that the mass transformation from amorphous into crystalline zeolite-type material takes place. After $24 \mathrm{~h}$ the major part of the solid has been converted into EMT-type zeolite.

Two crystallization mechanisms were observed in this study. The first one includes the propagation of crystalline phase through the gel network, which is confined spatially in the peripheral part of the gel particle (Figure 3). This mechanism dominates during the first stage of zeolite formation. The second mechanism proceeds via aggregation around a crystallization center and further growth of individual zeolite particles. This latter type of growth is considered a result of autocatalytic nucleation, where the viable nuclei liberated in the solution continue growing into crystals. We base this conclusion on the morphological features of the zeolite particles, which are dominated by round isometric aggregates. The isometric shape of crystalline aggregates (Figure 5) is a proof for non-confined growth that takes place in mother liquor. This mechanism dominates the second stage of zeolite formation when the mass transformation of amorphous to crystalline material takes place.

The physical evolution of the solid yielding EMT-type zeolite was investigated in details by a combination of electron microscopy techniques. Even this powerful technique could not identify 
the location and reveal the structure of the first zeolite cages. The appearance of the latter is a proof that particular zeolite structure has been formed and that most likely it will continue to grow into crystals. In order to correlate the spatial analysis by TEM with the temporal analysis of zeolite nucleation, we employed spectroscopic techniques that provided information on the formation of the first zeolite units. However, the Raman study did not provide valuable information for the induction period. The formation of larger ring structures that could be related to the formation of sodalite and EMT cages was detected only after $18 \mathrm{~h}$ of hydrothermal treatment.

In contrast, the hyperpolarized ${ }^{129} \mathrm{Xe} \mathrm{NMR}$ analysis revealed important changes in the pore structure of the solid in the very early stages of gel evolution. It was established that the first EMT cages are formed after $4 \mathrm{~h}$ of hydrothermal treatment. We estimate that the amount of Xe nuclei that can be detected by hyperpolarized ${ }^{129} \mathrm{Xe}$ NMR is around $10^{16}$. Using the Xe adsorption isotherm on EMT reference sample, we calculate that this amount corresponds to a few tens of micrograms of fully crystalline zeolite, which demonstrates the unraveled sensibility of hyperpolarized ${ }^{129} \mathrm{Xe}$ NMR analysis. In other words, since we have analyzed about $0.1 \mathrm{~g}$ of the 4 $\mathrm{h}$ sample, the method allows detecting the zeolite at concentration below $0.1 \mathrm{wt} \%$ from total mass of the sample. For instance, a method as powder XRD analysis which sensibility is between 3 and $5 \mathrm{wt} \%$ of the mass content cannot determine such amount, even in the case of highly crystalline product. The sensibility of Raman spectroscopy is similar to XRD analysis, which explains much earlier detection of zeolite phase by ${ }^{129} \mathrm{Xe}$ NMR analysis. The amount of crystalline material in the solid remains very low up to $18 \mathrm{~h}$ of synthesis. The slow nucleation in the system is a consequence most probably to the limited total volume of the shell, where initial nucleation takes place and the large particle size that hampers fast access of the reactant species to the core of the gel. The initial gel particles have a rim, built of heavily polymerized aluminosilicate, during the induction period this shell starts to get dissolved slowly as in certain areas the conditions for nucleation is attained. These areas, however, are limited in number because of the limited accessible surface of the gel. The interpretation that the nucleation takes place preferentially in the dense shell of gel particles is further supported by the changes of the mesopores in this part of the gel revealed by HP ${ }^{129} \mathrm{Xe}$ NMR.

We have observed the formation of particles in the voids deep inside the gel core (Figure 3c). These particles, which are most probably metastable sodium aluminate/silicates, are not likely to play key role in zeolite nucleation. Moreover, these particles are confined to the gel core and there is no communication between the mesopores and mother liquor. Thus, again our conclusion is that the nucleation was limited to the shell of the gel particles that in the present system was between 10 and $40 \mathrm{~nm}$ thick.

The applied value of this finding is that nucleation is a function of the size and morphology of initial gel particles. More precisely, by varying the conditions of preparation initial gel particles different in size and aggregation could be designed. This is supported strongly by a recent study based on a system similar to the one employed in the present one. ${ }^{[44]}$ Slow mixing of the sodiumsilicate and sodium-aluminate solutions at $277 \mathrm{~K}$ resulted in colloidal suspension of discrete gel particles; upon moderate heating the gel particles were converted in ultra small $(15 \times 2 \mathrm{~nm})$ EMT crystals. The crystals were single, non-aggregated with well-defined crystal morphology. In the present study the instant mixing of the two starting solutions at room temperature resulted in the large core-shell particles as described here. The ultimate product is heavily aggregated as the particles are much larger in size. The importance of initial gel preparation was further confirmed 
by the synthesis of ultra small FAU-type in Na-rich organic template-free free system. ${ }^{[45]}$ Again a suspension of very small gel precursor particles was stabilized by careful preparation of initial gel. The small discrete gel particles provide large accessible surface that leads to abundant nucleation in the system. The aggregation is also limited in such a system since each individual particle yields a single crystal.

\section{Conclusions}

The formation of EMT-type zeolite from an organic-template-free Na-rich gel system was studied. Complementary methods providing information on the long- and short-range structural order of the solid phase as well on the textural properties were employed. The crystal growth kinetics of EMT type was subjected to a detailed analysis. First zeolite cages were detected by $\mathrm{HP}{ }^{129} \mathrm{Xe}$ NMR analysis as early as $4 \mathrm{~h}$ of hydrothermal treatment. The induction period was relatively long $(18 \mathrm{~h})$, which is attributed to the small reaction surface area between the solid and mother liquor. The mass transformation of amorphous into crystalline material took place between 18 and $24 \mathrm{~h}$ of treatment.

An important finding that has critical implications on the kinetics and mechanism of both nucleation and growth is that the initial gel particles exhibit a core-shell structure. The core is rich of mesopores containing trapped mother liquor. The aluminosilicate shell is dense, impermeable for fluids and contains very limited number of mesocavities. This shell seems to be relatively stable and inert because after $18 \mathrm{~h}$ of hydrothermal treatment the core-shell structure is still preserved for most of the gel particles. The progressive erosion of the shell during the induction period opens access to mesopore volume of the gel. It was established that the moment when reactive species in the liquid part of the gel gain access to the core marks the moment of a radical surge in the rate of crystallization.

The time-series synthesis experiments in this study complemented by detailed characterization allowed to reveal the dynamics and kinetics of the process of zeolite nucleation and to localize spatially and temporally the formation of first nuclei. Our results prove unambiguously that inception of zeolite nucleation is localized in the shell of gel particles. The extremely thin surface zone is the place where the first nuclei are formed on. Thus the external surface area of the primary gel particles plays important role in the nucleation process and determines the kinetics of zeolite nucleation. Ensuing major implication of this study is that important zeolite properties such as size and level of aggregation can be controlled by proper design of the initial gel particles.

The mechanism observed in the crystalization of EMT-type zeolite could be generalized for aluminosilicate zeolites formed from alkali metal rich hydrogel systems.

\section{Materials and Methods}

Synthesis of EMT-type zeolite: Solutions of sodium aluminate and sodium silicate were prepared. The sodium aluminate solution (Solution $A$ ) was prepared by dissolving needed amounts of the sodium aluminate (Sigma-Aldrich, $w\left(\mathrm{Al}_{2} \mathrm{O}_{3}\right)=56 \%, w\left(\mathrm{Na}_{2} \mathrm{O}\right)=40 \%$ ) and sodium hydroxide (Prolabo, 97\%) in distilled water under vigorous stirring to give a clear solution. The 
sodium silicate solution (Solution B) was prepared by mixing appropriate amounts of sodium silicate (Prolabo VWR, $w\left(\mathrm{SiO}_{2}\right)=27 \%, w\left(\mathrm{Na}_{2} \mathrm{O}\right)=8 \%$ ), distilled water and sodium hydroxide. The two solutions were instantly mixed at room temperature and vigorously stirred for $1 \mathrm{~h}$ to homogenize. The final molar oxide gel composition was $18.45 \mathrm{Na}_{2} \mathrm{O}: 1.0 \mathrm{Al}_{2} \mathrm{O}_{3}: 5.15 \mathrm{SiO}_{2}: 240 \mathrm{H}_{2} \mathrm{O}$. Aliquots of initial gel were transferred in polypropylene vessels and the synthesis was conducted at $313 \mathrm{~K}$ for $2,4,6,12,18,24,30$, and $36 \mathrm{~h}$. The obtained solid phase was washed with demineralized water and dried at room temperature. A portion of initial gel $(0 \mathrm{~h})$ was washed and dried in similar manner.

\section{Characterizations}

${ }^{129} \mathrm{Xe}$ Nuclear magnetic resonance (NMR) spectroscopy. Prior to the NMR measurements samples were placed in an NMR tube with two Young valves, heated at $30 \mathrm{~K} / \mathrm{h}$ rate to $493 \mathrm{~K}$, and treated at this temperature overnight. All NMR experiments were carried out on Bruker AMX300 spectrometer (magnetic field: $7.04 \mathrm{~T},{ }^{129} \mathrm{Xe}$ resonance frequency $83.03 \mathrm{MHz}$ ). Optical polarization of xenon was achieved with an apparatus similar to that described by Nossov et al. (with the only difference, that the optical pumping cell was not in the fringe field of the spectrometer magnet, but inside the Helmholz coils). ${ }^{[58]}$ The Xe-He mixture containing $1 \%$ of

${ }^{129} \mathrm{Xe}$ polarized up to several percent at total pressure of 760 Torr was delivered at $300 \mathrm{~cm}^{3} / \mathrm{min}$ flow rate to the samples via plastic tubing. 64-512 FIDs were accumulated with $10 \mu \mathrm{s}(\pi / 2$ pulses) and $1 \mathrm{~s}$ delays. Some low-temperature experiments were performed without optical polarization (just by switching the lasers off) to distinguish the signals arising from thermally polarized xenon. The chemical shifts were referenced to the signal of xenon gas at ca. 8 Torr.

Unlike conventional or thermal ${ }^{129} \mathrm{Xe}$ NMR in which the nuclear spin polarization is governed by Boltzmann equilibrium, laser-polarized ${ }^{129} \mathrm{Xe}$ NMR is based on magnetic nuclear hyperpolarization obtained by magnetization transfer from $\mathrm{Rb}$ alkali-metal electronic spins optically pumped. The ${ }^{129} \mathrm{Xe}$ signal sensitivity is enhanced by a factor of $10^{3}-10^{5}$. Thus, the hyperpolarized (HP) ${ }^{129} \mathrm{Xe}$ NMR technique is particularly useful for systems with low surface areas and/or long spin-lattice relaxation times $\left(T_{1}\right)$, and has found widespread applications, for example, in characterization of surfaces, nanocrystals or thin films, porous materials, magnetic resonance imaging and medical imaging, sensors, etc. ${ }^{[52,53,59-61]}$

Transmission electron microscopy (TEM) study. Conventional TEM imaging was performed at the Central Facility for Advanced Microscopy and Microanalysis of the University of California at Riverside with an FEI CM300 TEM equipped with $\mathrm{LaB}_{6}$ cathode, and EDAX Genesis EDS system fitted with $30 \mathrm{~mm}^{2} \mathrm{Si}(\mathrm{Li})$ detector with resolution of $128 \mathrm{~nm}$ at $\mathrm{MnK}_{\alpha}$ at 200 and $300 \mathrm{kV}$ accelerating voltages. Samples were prepared by putting some of the unground synthesis powders in distilled water, dispersing them using ultrasonic agitation, and depositing a droplet of the resulting suspension onto $\mathrm{Cu}$ grids coated with a thin holey carbon support film. Images were recorded on Gatan MSC794 CCD camera in low-dose mode.

Further TEM imaging and electron tomography were performed using a JEOL 2100F microscope working at $200 \mathrm{kV}$, equipped with a Cs probe corrector and a GATAN Tridiem imaging filter. For the analyses, the zeolite samples were dispersed in ethanol (99.9\%) and then a drop of solution was deposited on a TEM grid covered by a holey carbon membrane. The emission current was kept constant at $\sim 160 \mu \mathrm{A}$. 
Electron tomography is using complex mathematical algorithms in order to extract the 3D information embedded in a tilt series of conventional 2D TEM projections. An ET analysis requires four major steps: i) tilt series acquisition (tilting the object inside the microscope and imaging the object at different tilting angles); ii) tilt series alignment (arranging all the images acquired with respect to a number of pre-defined fixed points); iii) reconstruction (using different mathematical algorithms to reconstruct the 3D structure of the object); iv) segmentation (removing the background signal from the reconstruction). What ET offers at the end of this procedure is a complete 3D representation of the object including surface topography and inside morphology." Conventional electron tomography series were acquired using a Gatan high tilt holder in the $\pm 65^{\circ}$ tilt range with a tilt step of $1.5^{\circ}$. The beam current at the fluorescent screen level was kept at $\sim 5 \mathrm{pA}$ (measured at $40 \mathrm{kx}$ magnification). After each 2 images acquired ( $\sim 30 \mathrm{~s}$ direct exposure) the beam was electronically blocked (blanking) for 1 minute allowing the accumulated charge to be dissipated, assuring minimal sample damage. The cryo-electron tomography was performed using a Gatan high tilt liquid nitrogen cryo-transfer holder at $203 \mathrm{~K}$ in the $\pm 60^{\circ}$ tilt range with a tilt step of $2^{\circ}$. The beam current at the fluorescent screen level was set at $\sim 8 \mathrm{pA}$ (measured at $40 \mathrm{kx}$ magnification). The tilt series alignments were performed with the IMOD software using $5 \mathrm{~nm}$ gold NPs as fiducial markers. ${ }^{[62]}$ The iterative reconstruction technique (SIRT) implemented in the Tomo3D program running on multicore computers was used for image reconstruction of the tomography data. ${ }^{[63]}$ The size of the TEM projections used for the reconstruction was $2 \mathrm{k} \times 2 \mathrm{k}$ pixels with a pixel size of $0.26 \mathrm{~nm} \times 0.26 \mathrm{~nm}$. The tomograms segmentation and porosity analysis was performed using Slicer3D program while the pore size distribution was calculated using the 3D object counter plugin in ImageJ software. Energy filtered TEM (EFTEM). Energy filtered TEM analysis was performed using a post-column Gatan Tridiem filter. The elemental maps for Si an Al were acquired using the three windows method in Gatan elemental map setup. The exact position of each window was: $\mathrm{Si}(111 \mathrm{eV}, 100 \mathrm{eV}, 90 \mathrm{eV})$ with a $10 \mathrm{eV}$ slit and $\mathrm{Al}(75 \mathrm{eV}, 59 \mathrm{eV}, 44 \mathrm{eV})$ with a $15 \mathrm{eV}$ slit. All the EFTEM images were $1024 \times 1024$ pixels in size.

\section{Complementary Methods}

Powder X-ray diffraction (XRD) analysis. The crystallinity of the samples was measured using a PANalytical X'Pert Pro diffractometer with $\mathrm{Cu} \mathrm{K} \alpha$ radiation $(\lambda=1.5418 \AA$, $45 \mathrm{kV}, 40 \mathrm{~mA})$. Scanning electron microscopy (SEM). The crystal size and morphology of the samples were studied by SEM. Electron micrographs were taken on a MIRA-LMH (TESCAN) scanning electron microscope equipped with a field emission gun. Dynamic light scattering (DLS) analysis. The hydrodynamic diameters of the nanoparticles in the suspensions were determined with a Malvern Zetasizer Nano. The analyses were performed on samples with original concentrations without any pretreatment of the colloidal suspensions (scattering angle $173^{\circ}$, HeNe laser with $3 \mathrm{~mW}$ output power at $632.8 \mathrm{~nm}$ wavelength). Chemical analysis. Elemental analysis of crystalline samples was performed by inductively coupled plasma-atomic emission spectroscopy (ICP-AES) using an OPTIMA 4300 DV (Perkin-Elmer) instrument. $N_{2}$ sorption analysis. The porosity of the samples was determined by recording the nitrogen adsorption/desorption isotherms using a Micrometrics ASAP 2020 volumetric adsorption analyzer. Samples were degassed at $573 \mathrm{~K}$ under vacuum overnight prior to the measurement. The specific surface area was calculated by the BET equation $\left(\mathrm{S}_{\mathrm{BET}}\right)$ and the micropore volume was evaluated by the $t$-plot method. Raman spectroscopy. Raman spectra of the samples were measured using Jobin Yvon Labram 300 spectrometer equipped with a confocal microscope. The 
measurements were done using a He-Ne laser with $632.8 \mathrm{~nm}$ wavelength. Each Raman spectrum was acquired for $60 \mathrm{~s}$. For each sample 5 spectra were collected and summed together for better signal resolution.

\section{Acknowledgements}

Financial support by the French Research Foundation (ANR) under contract ANR-12-IS08-000101 (Micro-Green) is gratefully acknowledged. Financial support under contract ANR-12-BS070029 (Catsyn-Biofuel) is also acknowledged.

\section{References}

[1] A. Corma, Chem. Rev. 1997, 97, 2373-2401.

[2] M. V. Landau, L. Vradman, V. Valtchev, J. Lezervant, E. Liubich, M. Talianker, Ind. Eng. Chem. Res. 2003, 42, 2773-2782.

[3] C. Martinez, A. Corma, Coord. Chem. Rev. 2011, 255, 1558-1580.

[4] V. Valtchev, G. Majano, S. Mintova, J. Perez-Ramirez, Chem. Soc. Rev. 2013, 42, 263290.

[5] D. Breck, Zeolite Molecular Sieves, John Wiley and Sons, New York, 1974.

[6] C. S. Cundy, P. A. Cox, Microporous Mesoporous Mater. 2005, 82, 1-78.

[7] M. D. Oleksiak, J. D. Rimer, Rev. Chem. Eng. 2014, 30, 1-49.

[8] J. W. Mullin, Crystallization, $4^{\text {th }}$ Edition, Butterworth -Heinemann, Oxford, 2001.

[9] M. E. Davis, Nature 2002, 417, 813-821.

[10] K. Moller, T. Bein, Chem. Soc. Rev. 2013, 42, 3689-3707.

[11] D. P. Serrano, J. M. Escola, P. Pizarro, Chem. Soc. Rev. 2013, 42, 4004-4035.

[12] F. Schüth, Cur. Opin. Solid State Mater. Sci. 2001, 5, 389-395.

[13] H. F. Greer, Mater. Sci. Tech. 2014, 6, 611-626.

[14] A. Palčić, B. Subotić, V. Valtchev, J. Bronić, CrystEngComm 2013, 15, 5784-5791.

[15] V. Valtchev, L. Tosheva, Chem. Rev. 2013, 113, 6734-6760.

[16] V. Valtchev, L. Tosheva, Chem. Mater. 2005, 17, 2494-2515.

[17] Y. Kalvachev, M. Jaber, V. Mavrodinova, L. Dimitrov, D. Nihtianova, V. Valtchev, Microporous Mesoporous Mater. 2013, 177, 127-134.

[18] Y. Bouizi, L. Rouleau, V. Valtchev, Microporous Mesoporous Mater. 2006, 91, 70-77.

[19] A. Corma, M. E. Davis, ChemPhysChem 2004, 5, 304-313.

[20] D. D. Kragten, J. M. Fedeyko, K. R. Sawant, J. D. Rimer, D. G. Vlachos, R. F. Lobo, M. Tsapatsis, J. Phys. Chem. B 2003, 107, 10006-10016.

[21] S. L. Burkett, M. E. Davis, Chem. Mater. 1995, 7, 1639-1650.

[22] W. H. Dokter, H. F. Van Garderen, T. P. M. Beelen, R. A. Van Santen, W. Bras, Angew. Chem., Int. Ed. 1995, 34, 73-75.

[23] B. J. Schoeman, J. Sterte, J. E. Otterstedt, Stud. Surf. Sci. Catal. 1994, 83, 49-56.

[24] B. J. Schoeman, O. Regev, Zeolites 1996, 17, 447-456.

[25] J. D. Rimer, J. M. Fedeyko, D. G. Vlachos, R. F. Lobo, Chem. Eur. J. 2006, 12, 29262934.

[26] S. A. Pelster, R. Kalamajka, W. Schrader, F. Schüth, Angew. Chem., Int. Ed. 2007, 46, 2299-2302. 
[27] L. Tosheva, B. Mihailova, L. H. Wee, B. Gasharova, K. Garbev, A. M. Doyle, Angew. Chem., Int. Ed. 2008, 47, 8650-8653.

[28] C. E. A. Kirschhock, R. Ravishankar, P. A. Jacobs, J. A. Martens, J. Phys. Chem. B 1999, 103, 11021-11027.

[29] T. Wakihara, S. Kohara, G. Sankar, S. Saito, M. Sanchez-Sanchez, A. R. Overwag, W. Fan, M. Ogura, T. Okubo, Phys. Chem. Chem. Phys. 2006, 8, 224-227.

[30] F. Wei, M. Ogura, G. Sankar, T. Okubo, Chem. Mater. 2007, 19, 1906-1917.

[31] T. M. Davis, T. O. Drews, H. Ramanan, C. He, J. Dong, H. Schnablegger, M. A. Katsoulakis, E. Kokkoli, A. V. McCormick, R. L. Penn, M. Tsapatsis, Nat. Mater. 2006, 5, 400-408.

[32] S. R. Bajpe, C. E. A. Kirschhock, A. Aerts, E. Breynaert, G. Absillis, T. N. Parac-Vogt, L. Giebeler, Chem. Eur. J. 2010, 16, 3926-3932.

[33] S. Bals, K. J. Batenburg, D. Liang, O. Lebedev, G. Van Tendeloo, A. Aerts, J. A. Martens, C. E. A. Kirschhock, J. Am. Chem. Soc. 2009, 131, 4769-4773.

[34] R. Szostak, Molecular Sieves: Principles of Synthesis and Identification, Van NostrandReinhold, New York, 1989.

[35] A. V. McCormick, A. T. Bell, C. J. Radke, J. Phys. Chem. 1989, 93, 1741-1744.

[36] A. Katović, B. Subotić, I. Šmit, Lj. A. Despotović, Zeolites 1990, 10, 634-641.

[37] M. Smaihi, O. Barida, V. Valtchev, Eur. J. Inorg. Chem. 2003, 2003, 4370-4377.

[38] V. Valtchev, S. Rigolet, K. N. Bozhilov, Microporous Mesoporous Mater. 2007, 101, 73 82.

[39] D. P. Serrano, M. A. Uguina, G. Ovejero, R. Van Grieken, M. Camacho, Microporous Mesoporous Mater. 1996, 7, 309-321.

[40] P. K. Dutta, J. Twu, J. Phys. Chem. 1991, 95, 2498-2501.

[41] B. Subotić, A. Graovac, Stud. Surf. Sci. Catal. 1985, 24, 199-206.

[42] R. W. Thompson, Zeolites 1992, 12, 837-840.

[43] S. Mintova, N. H. Olson, V. Valtchev, T. Bein, Science 1999, 283, 958-960.

[44] E.-P. Ng, D. Chateigner, T. Bein, V. Valtchev, S. Mintova, Science 2012, 335, 70-73.

[45] H. Awala, J.-P. Gilson, R. Retoux, P. Boullay, J.-M. Goupil, V. Valtchev, S. Mintova, Nat. Mater. 2015, 14, 447-451.

[46] F. Dougnier, J. Patarin, J.-L. Guth, D. Anglerot, Zeolites 1992, 12, 160-166.

[47] S. Liu, L. Li, C. Li, X. Xiong, F.-S. Xiao, J. Porous Mater. 2008, 15, 295-301.

[48] A. Haas, D. A. Harding, J. R. D. Nee, Microporous Mesoporous Mater. 1999, 28, $325-$ 333.

[49] V. Valtchev, K. N. Bozhilov, J. Phys. Chem. B 2004, 108, 15587-15598.

[50] P. K. Dutta, D. C. Shieh, M. Puri, Zeolites 1988, 8, 306-309.

[51] C. Li, Z. Wu, in Handbook of Zeolite Science and Technology (Eds.: S. M. Auerbach, K. A. Carrado, P. K. Dutta,), Marcel Dekker Inc., New York, 2003.

[52] F. Dougnier, J.-L. Guth, J. Chem. Soc., Chem. Commun. 1995, 951-952.

[53] C. J. Jameson, A. K. Jameson, R. E. Gerald, H.-M. Lim, J. Phys. Chem. B 1997, 101, 8418-8437.

[54] V. V. Terskikh, I. L. Moudrakovski, S. R. Breeze, S. Lang, C. I. Ratcliffe, J. A. Ripmeester, A. Sayari, Langmuir 2002, 18, 5653-5656.

[55] B. Subotić, J. Bronić, T. Antonić-Jelić, in Ordered Porous Materials (Eds.: V. Valtchev, S. Mintova, M. Tsapatsis), Elsevier, Amsterdam, 2009. 
[56] V. Nikolakis, D. G. Vlachos, M. Tsapatsis, Microporous Mesoporous Mater. 1998, 21, 337-346.

[57] D. P. Serano, R. van Grieken, J. Mater. Chem. 2001, 11, 2391-2407.

[58] A. Nossov, E. Haddad, F. Guenneau, A. Galarneau, F. Di Renzo, F. Fajula, A. Gedeon, J. Phys. Chem. B 2003, 107, 12456-12460.

[59] T. Brotin, J. P. Dutasta, Chem. Rev. 2009, 109, 88-130.

[60] A. Nossov, E. Haddad, F. Guenneau, C. Mignon, A. Gédéon, D. Grosso, F. Babonneau, C. Bonhomme, C. Sanchez, Chem. Commun. 2002, 2476-2477.

[61] A. Nossov, F. Guenneau, M.-A. Springuel-Huet, E. Haddad, V. Montouillout, B. Knott, F. Engelke, C. Fernandez, A. Gedeon, Phys. Chem. Chem. Phys. 2003, 5, 4479-4483.

[62] J. R. Kremer, D. N. Mastronarde, J. R. McIntosh, J. Struct. Biol. 1996, 116, 71-76.

[63] J. I. Agulleiro, J. J. Fernandez, Bioinformatics 2011, 27, 582-583. 


\section{Scheme and figure captions}

Figure 1. TEM images of the solid phase obtained in the system yielding EMT-type zeolite at 313 $\mathrm{K}$ : a) initial gel $(0 \mathrm{~h})$, b) $6 \mathrm{~h}, \mathrm{c}) 12 \mathrm{~h}, \mathrm{~d}) 18 \mathrm{~h}$, e) $24 \mathrm{~h}, \mathrm{f}) 36 \mathrm{~h}$. The white ellipsoids (c) and arrows (d) highlight the presence of crystalline non-porous areas (see the insets).

Figure 2. a) Conventional TEM image of a gel particle form the initial run $(0 \mathrm{~h})$ used for cryo-ET; b) $\mathrm{XY}$ slice through the reconstructed volume of the gel particle; c) general view after segmentation of the gel particle (pores are represented in dark grey and the gel body in semitransparent grey); d) pore size distribution in the gel particle extracted from the cryo-ET segmented data.

Figure 3. a) TEM image of a $6 \mathrm{~h}$ zeolite particles with a dual morphology: porous and non-porous (dashed rectangles); b) $12 \mathrm{~h}$ zeolite sample with a dual morphology (the inset is a HRTEM image of the microporous cages formed in the non-porous regions (dashed rectangle); c) and d) XY slices through the reconstructed volume of a $12 \mathrm{~h}$ zeolite sample.

Figure 4. a) Conventional TEM image at $0^{\circ}$ tilt of a gel particle from the sample treated hydrothermally for $12 \mathrm{~h}$; b) XY slice through the reconstructed volume of the particle in Figure 4a obtained by cryo-ET; c) digitally reconstructed gel particle after segmentation: pores are represented in dark grey and the gel body in semi-transparent grey; d) pore size distribution of the $12 \mathrm{~h}$ sample extracted from the cryo-ET data.

Figure 5. a) TEM image of a $24 \mathrm{~h}$ zeolite sample with its FFT inset; b) XY slice through the reconstructed volume of a $24 \mathrm{~h}$ zeolite sample, grey dotted line outlines the jagged outer edges of the aggregate particle; c) conventional TEM image of a $30 \mathrm{~h}$ zeolite sample with the prismatic structure highlighted with white dotted lines; d) ABSF filtered HRTEM image of a $30 \mathrm{~h}$ sample with its FFT inset.

Figure 6. ${ }^{129} \mathrm{Xe}$ NMR spectra versus temperature of Xenon adsorbed in the sample from the $36 \mathrm{~h}$ run duration. On the right hand side, spectra recorded with the lasers off (for $T \leq 213 \mathrm{~K}$ ). A spectrum of EMT sample synthesized with 18-crown-6 ether is shown by a dashed line. The intensity of the spectra is arbitrary.

Figure 7. Chemical shift variation of the NMR peaks versus temperature for the experimental samples obtained in different synthesis run duration (h) compared to the reference EMT sample synthesized with 18 -crown-6 ether.

Figure $8 .{ }^{129} \mathrm{Xe}$ NMR spectra recorded at $193 \mathrm{~K}$ of xenon adsorbed in the initial gel and samples obtained after various synthesis times. The signal characteristic of the EMT structure is highlighted with squares and the lines corresponding to amorphous phase not well structurally organized are surrounded by a rectangle. The intensity of the spectra is arbitrary. 
Table of contents

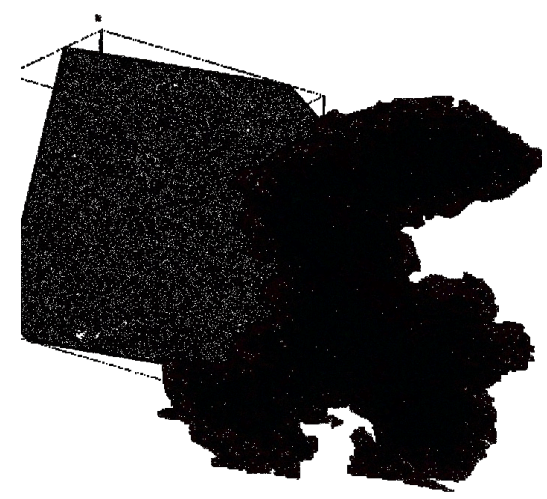

View inside zeolite precursor gel particle. Longitudinal slice through the reconstructed volume of a zeolite precursor gel particle and its 3D model representing the intraparticle pores (blue) and the gel body (transparent red) was obtained using TEM tomography. The principle aspects and constrains of the dynamics and kinetics of zeolite nucleation in hydrogel systems are analyzed on the basis of a model Na-rich aluminosilicate system.

Keywords: zeolites, crystal growth, nanoparticles 